Torres Nabel, L. (2015): Ensayo Redes sociales, popularidad e influencia social. El caso de la ciberprotesta contra la Ley de Telecomunicaciones en México, 2014, Revista Mediterránea de Comunicación, 6 (1), 177-185.

Vesnic-Alujevic, L. (2012): Political participation and web 2.0 in Europe: A case study of Facebook, Public Relations Review, 38(3), 466-470.

Vidales Bolaños, M, y Sádaba Chalezquer, C. (2017). Connected Teens: Measuring the Impact of Mobile Phones on Social Relationships through Social Capital, Comunicar, 25(53),19-27.

Zaheer, L. (2016). Effects of watching political talk shows on political efficacy and political participation, Journal of Political Studies, 23(2), 357-372.

Zhou, Y., y Pinkleton, B., (2012). Modeling the effects of political information source use and online expression on young adults' political efficacy, Mass Communication and Society, 15(6), 813-830.

Žižek, S.(2008): En defensa de la intolerancia Madrid: Ediciones Sequitur.

\section{Estrategias europeas contra el discurso del odio}

Begoña Pérez Calle ${ }^{7}$

María Gómez y Patiño ${ }^{8}$

Miguel Ángel Esteban-Navarro ${ }^{9}$

\section{Resumen}

El objetivo es presentar un panorama global de las principales estrategias que se adoptan en Europa para frenar y contrarrestar los discursos de odio. Se realiza una reflexión crítica a partir de una selección de documentación oficial y literatura académica más relevantes. Se destacan, entre otras medidas, la necesidad de aplicar el marco jurídico común europeo y formar una ciberopinión pública mediante la educomunicación y la lucha contra la desinformación. Se concluye que las instituciones europeas deben desarrollar una estrategia común y global en la lucha contra el discurso del odio, que integre las intervenciones parciales en diversas áreas y las diferentes iniciativas nacionales.

Palabras clave: Discurso del odio. Delito de odio. Desinformación. Opinión pública. Redes sociales. Educomunicación. Europa.

7. Profesora Titular de la Universidad de Zaragoza. Doctora en Economía por la UZ (2010). Investigadora en Historia del pensamiento económico, Historia de la Economía Historia del periodismo, Historia delas ideas políticas y Medios de comunicación de masas. Ha escrito numerosas publicaciones sobre análisis de discursos políticos y económicos, el papel de los comunicadores en la difusión del pensamiento y de la mujer en la investigación económica. Presidenta de la ONGD Dono-Manga y técnico responsable de sus proyectos de cooperación al desarrollo desde 2011. Departamento de Análisis Económico, Universidad de Zaragoza. Correo electrónico: bperez@unizar.es

8. Profesora Contratada Doctora Interina. Doctora en Ciencias de la Información por la UCM (1996). Coordinadora del Grado de Periodismo de la Universidad de Zaragoza. Ha publicado diversos libros y artículos académicos. Ha trabajado sucesivamente como Periodista y Directora de Comunicación. Fundadora del Seminario Permanente Estudios sobre la Mujer (Madrid, 1998). Ha participado en diferentes proyectos nacionales e internacionales. Es socia de DIRCOM, APA, FAPE, ACOP, AAS, etc. Área de Periodismo, Universidad de Zaragoza. Correo electrónico: mariagp@unizar.es

9. Profesor Titular de Universidad. Doctor en Historia Contemporanea por la UZ (1991). Coordinador de Máster en Consultoría de Información y Comunicación Digital de la Universidad de Zaragoza. Enseña e investiga en Inteligencia Estratégica y Competitiva, Servicios de Inteligencia y Gestión de Información y de Documentos. Ha publicado más de 30 trabajos, participado en 20 proyectos y contratos de investigación y dirigido 7 tesis doctorales. Posee amplia experiencla en la planificación de unidades de Inteligencia Competitiva y la elaboración de informes de inteligencia. Ha formado analistas en España y Latinoamérica. Trabaja en el estudio de las interacciones entre información, comunicación e inteligencia en la sociedad y las organizaciones. Departamento de Ciencias de la Documentación, Universidad de Zaragoza Correo electrónico mesteban@unizar.es 


\section{European strategies against hate speech}

\section{Abstract}

Our aim is to introduce a global overview of the main strategies adopted in Europe to stop and counteract hate speech. A critical reflection is made, based on a selection of the most relevant official documentation and academic literature. Among others, it highlights the need of applying the common European legal framework and creating a public cyber-connection through educommunication (media literacy) fighting against misinformation. As conclusion, the European institutions must develop a common and global strategy to eradicate hate speech, which integrates partial interventions in different areas and different national initiatives.

Keywords Hate speech. Hate crime. Disinformation. Public opinion. Social networks. Educommunication (media literacy). Europe.

\section{Introducción}

discurso del odio, que parecía superado en Europa tras el final de la Segunda Gue-

rra Mundial, invade de nuevo de modo preocupante el viejo continente, con especial

virulencia desde la crisis de 2008. Se trata de un discurso que busca generar en el receptor un profundo sentimiento de repulsa hacia un colectivo, sobre el que se proyecta la responsabilidad de las amenazas o de los males, reales o supuestos, que cree sufrir aquel. Estamos ante un fenómeno posiblemente tan viejo como las civilizaciones humanas, basadas durante siglos en la diferencia entre el heleno (el que habla griego) y el bárbaro (el que habla en lengua inteligible), en terminología acuñada en la Grecia Clásica, que transmutó a partir de la Edad Media y hasta nuestros días en la confrontación entre el nosotros y el extraño, el diferente, el marginal o, directamente, el excluido.

Las sociedades democráticas abiertas, plurales e integradoras que se construyeron con grandes dificultades a lo largo de los últimos decenios del siglo XX en Occidente con una vocación universal, ampliando a toda la humanidad los conceptos de dignidad natural y de derechos civiles que alumbró la Ilustración, corren el riesgo de involucionar en sociedades con claras tendencias al cierre de sus fronteras físicas y mentales, la invisibilización del otro y finalmente a la exclusión. La proliferación de ideas, actitudes, mensajes y comportamientos ligados a la incitación al odio hacia un tercero, definido o dejado a posta en una vaga indefinición, en los espacios verbales y no verbales, en los medios informativos, las redes sociales y los discursos sociales, políticos y económicos, aparece al mismo tiempo como motor, expresión y amplificador de ese proceso de cierre y repliegue que amenaza a las sociedades de Europa y de América. Las manifestaciones de odio o de discriminación existen desde antiguo, pero los nuevos medios permiten una mayor y más rápida diseminación, presentando el discurso del odio uno de sus peores perfiles, el conocido como ciberodio. El odio ha aparecido en las redes sociales como discurso y como delito, con los consiguientes efectos negativos psicológico-sociales e individuales de distinto alcance.

Afortunadamente, también se ha adquirido conciencia del peligro que entrañan las expresiones de odio y discriminación. El discurso y el delito del odio son objeto de interés trans- 
versal durante los últimos años para diversas disciplinas como el Derecho, la Comunicación, la Educación, la Sociología, la Psicología Social, las Ciencias Políticas... interesadas en comprender su origen, implicaciones y mecanismos. De modo paralelo y con apoyo en los hallazgos de esas disciplinas, los poderes públicos europeos se están preocupando por la identificación y el análisis del odio, la presentación de iniciativas y la adopción de medidas destinadas a su prevención. Del trabajo conjunto de instituciones como las Naciones Unidas, el Consejo de Europa o la Unión Europea han aparecido durante los últimos años herramientas de apoyo, especialmente de naturaleza jurídica y protocolos de actuación sobre el terreno.

Aquí nos ocupamos de presentar y reflexionar, a partir del estudio de la documentación oficial y la literatura académica más relevantes, sobre algunas de las propuestas y actuaciones más destacadas para contrarrestar la expansión del discurso del odio en Europa.

\section{Concepto de discurso de odio}

Es importante comenzar delimitando los conceptos, puesto que frecuentemente se cruzan y confunden los significados de términos como odio, discurso de odio, y delito de odio. Solamente conociendo bien el problema se podrán desarrollar las herramientas de lucha apropiadas.

La expresión "discurso de odio" cobró fuerza en la década de 1990 tomando el testigo al concepto "incitación al odio". El término hace referencia a un conjunto de manifestaciones con sentido discriminador y ofensivo dirigidas contra determinadas personas o colectivos de personas, que no merecen protección por parte de nuestros ordenamientos constitucionales ni se amparan en el ejercicio de la libertad de expresión. La recurrencia del término presenta en los últimos treinta años un crecimiento notable y constante, como permite comprobar la evolución de sus apariciones en los textos en lengua inglesa en Google Books (figura 1).

Figura 1: Apariciones del término hate speech en libros en lengua inglesa.

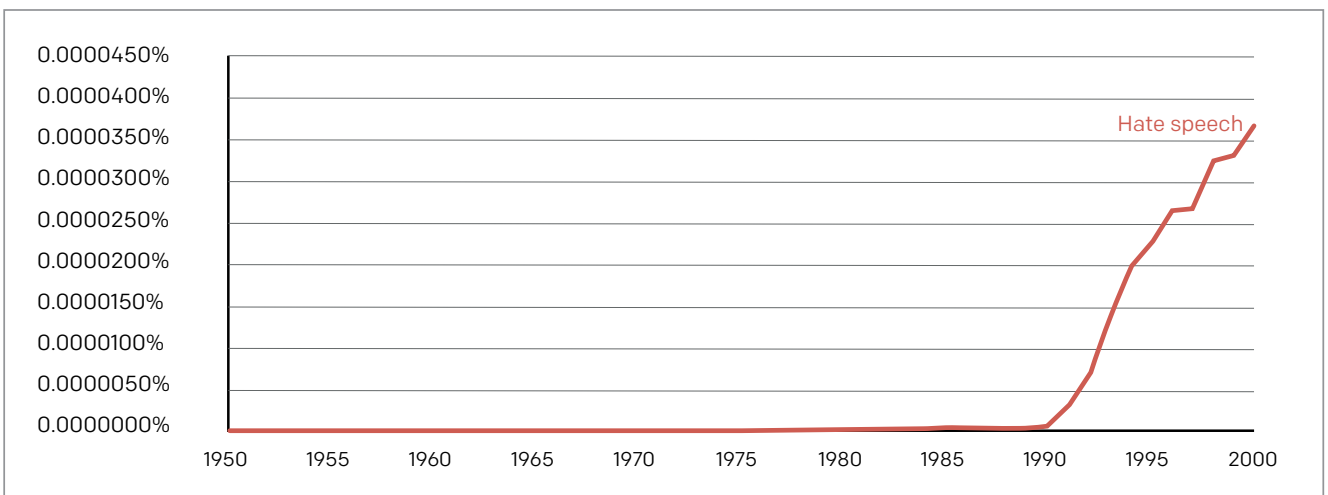

Fuente: Google Books, Ngram Viewer, 2019, https://tinyurl.com/y6rmw4tp
Las recientes investigaciones de Bhikhu Parekh profundizan en el discurso de odio vinculándolo con la estigmatización de personas o grupo de personas procedente de interpretaciones de una serie de características o condiciones, tanto rasgos particulares como raza, etnia, género, religión, nacionalidad u orientación sexual (Parekh, 2012, p. 214). Se configura de este modo un modelo de discurso con tres características fundamentales:

- Va dirigido contra cierto grupo de personas identificado con precisión (judíos, musulmanes, homosexuales...) y nunca contra la sociedad en general.

- Una vez establecido el objetivo se procede a una asignación de algunos estereotipos denigrantes.

- Asignados los estereotipos se juzga al grupo como no integrable a la sociedad y se le condena a ser tratado con desprecio y hostilidad.

La configuración de un discurso basado en el ataque a los diferentes, los pobres o las minorías, acompaña a la sociedad desde tiempos antiguos; sin embargo, es preciso hacer una reflexión sobre las modificaciones que presenta y su prevalencia actual, teniendo en cuenta los avances en el respeto a los derechos humanos y la adquisición de conciencia sobre lo que la sociedad puede o no puede tolerar (Pérez Calle, 2018, p. 373). La principal diferencia que se destaca frente al pasado es que se observa una evolución de lo que antiguamente podría haber sido un discurso de marginación o desprecio, hacia el odio subyacente que se observa en el discurso actual. Asimismo, a pesar de los muchos esfuerzos emprendidos en la segunda mitad del siglo XX para la superación de este discurso, el ciberespacio y el uso de las redes sociales han llevado a un crecimiento muy significativo del problema. Los estereotipos del desprecio han experimentado gran difusión y visibilidad a través de los nuevos medios relacionales, configurando el sustrato para el discurso en redes. Además, a los viejos tópicos de racismo, antisemitismo o revisionismo histórico se añaden otros nuevos en el siglo XXI, especialmente en Europa y Estados Unidos, como el ataque a minorías religiosas, inmigrantes, colectivos LGBT, ancianos, minusválidos, personas en exclusión, etc.

Por último, también es preciso distinguir el discurso de odio del delito de odio, ya que el primero no siempre es una categoría del segundo.

\section{El discurso y el delito de odio en el marco jurídico europeo}

Diversas instituciones de Europa tienen en cuenta las manifestaciones de odio como un problema genérico del que se debe ocupar el legislador. Existe también una clara voluntad de legislar a nivel europeo con objeto de crear un marco jurídico común sobre este asunto, que obligue a todos los países. Según la actual doctrina jurídica europea, los delitos de odio se caracterizan por la presencia de dos elementos: la existencia de una 
infracción penal (intimidación, amenazas, daños a la propiedad, asesinato...) motivada por razones discriminatorias.

El Comité de Ministros del Consejo Europeo fue pionero con la recomendación n. $\mathrm{R}$ (97) 20, de 30 de octubre de 1997, a los Estados miembros, que incluía como discurso del odio "todas las formas de expresión que difunden, incitan, promueven o justifican el odio racial, la xenofobia, el antisemitismo y otras formas de odio racial y de intolerancia, incluyendo: la intolerancia expresada a través de un nacionalismo agresivo y etnocéntrico, la discriminación y la hostilidad contra minorías, los inmigrantes y personas de origen inmigrante" (Consejo Europeo, 1997).

Posteriormente, el Consejo Ministerial de la Organización para la Seguridad y la Cooperación en Europea (OSCE) celebrado en Maastricht en 2003 fue la primera institución europea en adoptar acuerdos sobre los delitos de odio. Estos delitos fueron definidos por Decisión no 4/2003 de la OSCE como: "toda infracción penal, incluidas las cometidas contra las personas o la propiedad, donde el bien jurídico protegido, se elige por su, real o percibida, conexión, simpatía, filiación, apoyo o pertenencia a un grupo. Este grupo se basa en una característica común de sus miembros, como su raza, real o percibida, el origen nacional o étnico, el lenguaje, el color, la religión, la edad, la discapacidad, la orientación sexual u otro factor similar" (OSCE-ODIHR, 2003). Es decir, siempre ha de tratarse de infracciones tipificadas en los códigos penales, pero que no tienen por qué ser expresivas, caracterizadas por ciertas razones discriminatorias bajo las que actúa el delincuente, siempre basadas en ciertas características de la persona o grupo contra quien se comete el delito. Por otra parte, manifestaciones reconocidas como discurso del odio pueden no constituir una infracción penal, como explica con detalle la Oficina para Instituciones Democráticas y Derechos Humanos de la OSCE (OSCE-ODIHR, 2009).

Las expresiones de odio experimentaron un crecimiento importante a raíz del desarrollo de la sociedad de la información. Por ello, el 28 de enero de 2003, el Protocolo adicional al Convenio sobre la ciberdelincuencia relativo a la penalización de actos de índole racista y xenófoba cometidos por medio de sistemas informáticos del Consejo de Europa apuntó al discurso de odio. Este fue definido como "todo material escrito, toda imagen o cualquier otra representación de ideas o teorías, que propugne, promueva o incite al odio, la discriminación o la violencia, contra cualquier persona o grupo de personas, por razón de la raza, el color, la ascendencia o el origen nacional o étnico, así como por la religión en la medida en que ésta se utilice como pretexto para cualquiera de esos factores" (Consejo Europeo, 2003) Introduce así dos elementos que coinciden con el modelo de Bhikhu Parekh: primero, que las conductas expresivas han de diri- girse contra una persona o grupo de personas; y, segundo, se especifica con claridad que la motivación ha de encontrarse en determinadas circunstancias discriminatorias.

Ese mismo año el Tribunal Europeo de Derechos Humanos reconoció como discurso del odio "todas las formas de expresión que propaguen, inciten, promuevan o justifiquen el odio basado en la intolerancia (incluida la intolerancia religiosa)" (STEDH, 2003).

Doce años después, la Recomendación General n. 15 sobre líneas de actuación para combatir el discurso del odio de la Comisión Europea contra el Racismo y la Intolerancia, del 8 de diciembre de 2015, ha definido como discurso del odio: "el uso de una o más formas de expresión específicas -por ejemplo, la defensa, promoción o instigación del odio, la humillación o el menosprecio de una persona o grupo de personas, así como el acoso, descrédito, difusión de estereotipos negativos o estigmatización o amenaza con respecto a dicha persona o grupo de personas y la justificación de esas manifestaciones- basada en una lista no exhaustiva de características personales o estados que incluyen la raza, color, idioma, religión o creencias, nacionalidad u origen nacional o étnico, al igual que la ascendencia, edad, discapacidad, sexo, género, identidad de género y orientación sexual" (Consejo Europeo, 2015).

Conviene advertir que, a pesar de esta doctrina jurídica, la identificación y la lucha de los delitos de odio todavía presentan en Europa dificultades derivadas de la falta de reconocimiento de este tipo de delitos en las estadísticas públicas y oficiales, que son fundamentales para conocer el volumen aproximado de criminalidad (López Ortega, 2017). El reflejo estadístico es un paso imprescindible para concienciar a la sociedad europea en su conjunto sobre el problema, guiar una actuación más decidida de las fuerzas y cuerpos de seguridad del Estado y poder perfeccionar el marco jurídico actual, en el ámbito más amplio del Consejo de Europa.

Pero el discurso del odio no es un asunto de índole exclusivamente jurídica y legal. Por eso, a pesar de estos avances en la normativa europea, coincidimos con F. Rey (2015) en que no podemos dejar al Derecho Penal solo ante este problema. Entre otras cosas porque es un fenómeno social directamente vinculado con la política, la sociología y, sobre todo, la opinión pública.

\section{La ciberciudadanía y su cibercomunicación}

Existe una tendencia generalizada a creer que la utilización de internet y de las redes sociales ha modificado la percepción de la opinión pública en el mundo occidental. La comunicación social va cambiando en función del momento histórico y de las tecnologías 
disponibles y, con ella, la comunicación política, que se caracteriza por la forma en que se trasmite el mensaje (Blumler, 2016). En el último decenio, los políticos y los partidos han innovado su comunicación política mediante la utilización de todas las redes y herramientas digitales disponibles, dando lugar a lo que ya se conoce como inequívocas cibercampañas electorales, como las campañas electorales de 2015 y 2016 en España (Dader y Campos, 2017).

La hiperconectividad de Internet, el uso de las redes sociales, la conversión de los teléfonos móviles en herramienta indispensable de la vida cotidiana y la expansión de la mensajería electrónica instantánea, ofrecen al consumidor de mensajes la posibilidad real de acceder de modo inmediato a información de actualidad, de aumentar y diversificar sus fuentes de información, de convertirse en productor y emisor de mensajes, e incluso de poseer en potencia la capacidad de influir en la elaboración del relato político y en la creación de la opinión pública. Todos podemos convertirnos al mismo tiempo en prosumers, consumidores y productores (influencers, youtubers, instagrammers...) de información de modo simultáneo y con bajo coste en tiempo y en recursos. Twitter, que permite crear, difundir y consumir mensajes breves con alta carga informativa e impacto emocional con gran rapidez, es posiblemente la red social más ampliamente utilizada en Europa para la comunicación política; como revela que haya sido la más usada en las últimas campañas electorales en España (Abejón, Tejedor, Gómez y Patiño, Risueño, Osuna, y Dader, 2017).

Esta nueva comunicación política ha dado lugar a una opinión pública 4.0, que es el resultado de una práctica basada en la penetración del mensaje por vía digital a través de las redes sociales, cuyo sustento es una sofisticada utilización de la inteligencia artificial, de base algorítmica, matemática y psicológico-social (Gómez-Patiño, Nogales-Bocio y Esteban-Navarro, 2018).

Sin embargo, la emergencia de una ciberpolítica no conduce necesariamente a la existencia de una ciberdemocracia (Túñez y Sixto, 2012). De hecho, no ha aparecido una ciberciudadanía que permita hablar de la existencia de una verdadera ciber-participación política, cuyo surgimiento acarrearía inevitablemente la presencia de un activo ciber-compromiso social (ciber-engagement). Estas ausencias permiten afirmar que la actual opinión pública 4.0 todavía está lejos de ser una verdadera opinión pública, debido entre otras causas al fenómeno conocido como la desinformación. La capacidad que revelan las redes sociales para influir en las emociones y las conductas de los ciudadanos atraen a diversos agentes a organizar operaciones de desinformación masivas encubiertas, que encuentran en esas redes al mismo tiempo un eficaz medio de penetración y un peligroso caldo de cultivo del discurso del odio, que tiene como aliado al anonimato con el que los ciberciudadanos se comunican entre ellos.
Por desinformación se entiende un proceso de comunicación consciente e intencionado emprendido por un emisor generalmente contra una diana, que induce al engaño o al error, y que busca manipular a un colectivo amplio mediante técnicas de viralización de mensajes. La desinformación no se dirige a audiencias, sino a comunidades buscando provocar una polarización con objeto de alcanzar un fin que aporte un beneficio político o económico. Los discursos del odio encuentran en la desinformación un cauce efectivo para llegar a la sociedad y las operaciones de desinformación suelen hacer uso del discurso del odio como un recurso recurrente para lograr sus fines. La desinformación y los discursos del odio coinciden en su preferencia por la emisión de mensajes disruptivos en escenarios de confrontación tras un análisis y detección de las vulnerabilidades de sus objetivos, donde esparcen información falsa o manipulada sobre diversos colectivos, aludiendo a características distintivas amplificadas o distorsionadas que les hacen responsables de acontecimientos que presentan una amenaza o tienen un impacto negativo en la vida y la situación de las comunidades a las que dirigen sus mensajes.

Las sociedades abiertas se caracterizan por la existencia de ciudadanos con conciencia moral, que inquieren sobre la realidad, que intentan construir su propio criterio, que buscan y cultivan la relación y la comunicación en libertad con el otro y que defienden su derecho a exponer y defender libremente sus ideas y opiniones. Esto permite el surgimiento de una opinión pública crítica, sin la cual no puede existir la democracia.

Para ello, es condición indispensable disponer de unos medios de comunicación independientes y garantizar el acceso a información de calidad; de lo contrario, surge una pseudo-opinión pública manipulada por malas praxis informativas. Sin embargo, estas dos fortalezas de las sociedades democráticas, un ciudadano que se pregunta y la garantía de libertad de expresión y de información, convierten al mismo tiempo a estas sociedades en vulnerables, ya que la búsqueda y el consumo espontáneos de información por los ciudadanos facilitan a terceros sembrar dudas y producir confusión y que todos seamos más receptivos a rumores, mensajes falsos y operaciones de influencia.

\section{Acciones contra el discurso y el delito de odio}

Para hacer frente al discurso del odio que va ganando espacio en el escenario europeo, especialmente en las redes sociales, se considera imprescindible contar con prácticas destinadas a mejorar la calidad de la información, desmentir los bulos de la desinformación y sancionar económicamente e incluso penalmente a los incitadores al odio. En este sentido, la preocupación por la proliferación de noticias falsas que 
generan efectos perversos (deseados o no) ha dado como resultado la publicación de un manual por parte de la UNESCO (2018) para hacer frente a la desinformación, que distingue claramente no solo la diferencia de los discursos y las diversas malas praxis informativas, sino también las intenciones y sus efectos (figura 2).

Figura 2: Desorden de la información.

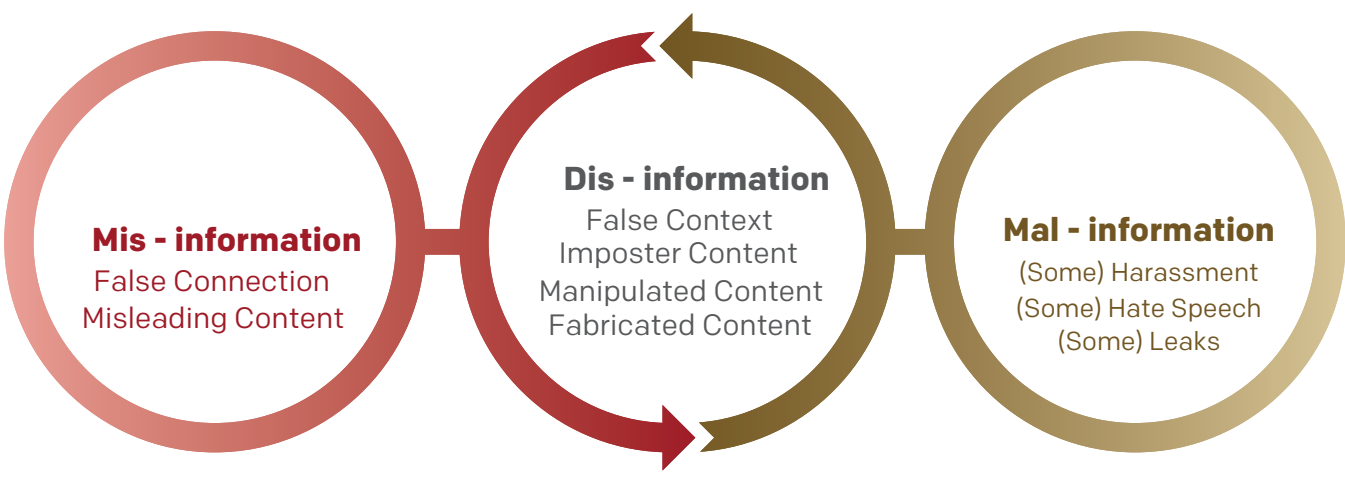

Fuente: UNESCO, 201

Asimismo, se trabaja en terrenos tecnológicos como la investigación en big y open data (Gil de Zúñiga y Diehl, 2017), la inteligencia artificial, el neuromarketing (Gómez y Patiño y Bandrés, 2014) y el análisis automático del contenido en redes sociales (De Vreese, 2017) con objeto de que sean las propias herramientas informáticas las que identifiquen y bloqueen noticias falsas o mensajes de odio. Las tecnologías también deben servir para enriquecer el espectro de la información que recibe un ciudadano, en lugar de reforzar ideas preconcebidas. Como advierte el Centro Criptológico Nacional de España (2019, p. 30): "Los algoritmos que utilizan las nuevas plataformas de comunicación digital se han convertido en aliados involuntarios de las campañas de desinformación. Estas tecnologías no priorizan que el usuario final reciba informaciones variadas y plurales sobre la actualidad política, social o económica. Por el contrario, están diseñadas para que el usuario reciba e interactúe, únicamente, con mensajes que potencialmente pueden ser de su agrado y reafirmen sus ideas".

La lucha contra cualquier tipo de incitación o discurso de odio hasta ahora ha adquirido un carácter voluntario para las redes sociales, si bien la Comisión Europea se ha mostrado partidaria de la posibilidad de crear una legislación que garantice la eliminación de contenidos ilegales. El 24 de marzo de 2016, a resultas del atentado en Bruselas dos días antes, el Consejo de Europa apuntó la importancia de prevenir la difusión de los discursos de odio, acordando que "la Comisión intensificará la coopera- ción con empresas del sector informático en el marco del Foro de Internet de la UE, con el fin de combatir la propaganda terrorista y desarrollar para junio de 2016 un código de conducta contra la incitación al odio en Internet" (Consejo Europeo, 2016). Dos meses después, la Comisión Europea suscribió con Facebook, Microsoft, Twitter y YouTube un Código de Conducta voluntario con el objetivo de contrarrestar la incitación al odio online, para ayudar a los usuarios a notificar discursos e incitaciones, mejorar el apoyo a la sociedad civil y la coordinación con las autoridades nacionales (Comisión Europea, 2016).

Este código es presentado como una alternativa a la reglamentación de contenidos. Las redes sociales han mejorado la gestión de dichos contenidos ilegales en sus plataformas: empresas como Facebook, Twitter o YouTube son ahora más veloces cuando se trata de retirar publicaciones que propasan la libertad de expresión y, en especial, cuando son claras incitaciones al odio.

En diciembre de 2016, junio de 2017 y enero de 2018, la Comisión Europea presentó resultados de tres rondas evaluativas de la implementación del Código de Conducta que mostraron un progreso continuo. El 1 de marzo de 2018 se publicó una Recomendación de la Comisión sobre medidas para combatir efectivamente el contenido ilegal en línea. En febrero de 2019 la Comisaria Europea de Justicia, Consumidores e Igualdad de Género, Věra Jourová, declaraba: “hoy, después de dos años y medio, podemos decir que encontramos el enfoque correcto y establecemos un estándar en toda Europa sobre cómo abordar este grave problema, mientras protegemos por completo la libertad de expresión".

Sin embargo, la decisión de la Comisión Europea de confiar un papel tan importante a las empresas privadas es susceptible de crítica por asignar a las grandes plataformas tecnológicas papeles de legisladores, jueces y ejecutores, sin pasar por la supervisión del poder judicial.

Por eso, la regulación del mercado europeo único digital se considera también necesaria, de acuerdo con un informe de Divina Frau-Meigs para el Parlamento Europeo (2018). Entre las principales medidas implantadas en los últimos años se encuentra la directiva de comercio electrónico, que exige una mayor diligencia a operadores como Google, Facebook y Twitter para detectar y notificar fraudes y contenidos ilícitos.

Por su parte, la directiva que regula los servicios de medios audiovisuales incluye en su versión revisada plataformas con contenido audiovisual, como YouTube, y las coloca bajo la tutela de las autoridades de medios. La directiva de seguridad de la red 
y la información obliga a los operadores y las plataformas a ser transparentes sobre las amenazas cibernéticas e informar sobre sus violaciones de seguridad. La reciente directiva sobre derechos de autor, que tanta controversia causa, intenta también involucrar a las plataformas exigiendo la implementación de herramientas para la detección automática de contenido ilegal. Por último, el reglamento general de protección de datos en la Unión Europea ofrece una serie de garantías y protecciones a los usuarios en su relación con las plataformas digitales, exigiendo que estas sean explícitas y exhaustivas sobre el uso planificado de los datos recopilados.

Las medidas de autorregulación junto con las legales pueden tener cierta efectividad; sin embargo, se debe ser consciente de que eliminar la incitación al odio de la web no es lo mismo que eliminarla de la sociedad.

Por eso, una acción que se revela muy importante para cooperar en la formación de una opinión pública 4.0 crítica es reforzar la confianza de los ciudadanos en las instituciones, con el fin de minimizar los efectos perversos de la desinformación y los discursos del odio. El hecho de que los ciberciudadanos estén permanentemente invadidos por mensajes de diferente tipo, no siempre pacificadores ni amables, ha generado en un contexto de crisis social y económica la pérdida de confianza en las instituciones.

La confianza social de los ciudadanos respecto al Gobierno, las instituciones del sistema político y los líderes de un país varía en función de su Índice de Desarrollo Humano (IDH), apreciándose una relación proporcional entre esa confianza y este índice, como revela un reciente estudio realizado sobre 22 países (Gil de Zúñiga, Ardèvol-Abreu, Diehl, Gómez Patiño y Liu, 2019).

La necesidad de diseñar e implantar estrategias tendientes al fortalecimiento de la opinión pública y a combatir la acción de la desinformación en general y la expansión de los discursos del odio en particular, también han encontrado eco en las Estrategias de Seguridad Nacional de diversos países europeos; sobre todo cuando se trata de afrontar amenazas de operaciones de desinformación de origen exterior que tratan de influir en la sociedad, especialmente durante momentos tan cruciales para un país como son los procesos electorales.

Francia ha sido el primer país en incluir la desinformación que actúa a través de internet como una amenaza que puede desembocar en una forma de subversión blanda, dirigida a acrecentar las tensiones internas de la sociedad, influir en ella, minar sus fuerzas morales y favorecer su parálisis política (République Française, 2017). Unos meses después España también contempló en su Estrategia de Seguridad la desinfor- mación como un gran desafío que utiliza el ciberespacio como su campo de batalla y que amplifica la incertidumbre de la sociedad y pone en riesgo la propia privacidad de los ciudadanos (Gobierno de España, 2017). El discurso del odio no aparece enunciado de manera explícita en estos documentos estratégicos de carácter oficial como amenazas, pero sí el principal recurso para su expansión: la desinformación en internet.

Sin embargo, sin desestimar la importancia de todas las acciones anteriores, consideramos que en última instancia la estrategia más eficaz a mediano plazo es reforzar a los propios ciudadanos, dotándoles de competencias digitales y analíticas que configuren un pensamiento crítico que les permita buscar la información que necesitan y analizar la información que reciben. En este escenario aparece la educomunicación como un recurso al alcance de cualquier institución, aunque de difícil implantación regular, que puede contribuir a combatir los discursos de odio indeseables, porque crearán a su vez una herramienta útil que formará una opinión pública crítica dentro de la era 4.0 .

La educomunicación o educación para los medios es, según la Association for Media Literacy (AML), con sede en Toronto, "el estudio de los medios de comunicación en contextos educativos con el fin de conocer las construcciones de la realidad social que hacen los diferentes medios" (cit. Gómez y Patiño, 2015). Plantea una interrelación circular y bidireccional entre medios de comunicación, sociedad y educación, donde la adquisición por los ciudadanos de competencias informacionales y mediáticas se considera clave para crear una verdadera opinión pública.

Por ello, la educomunicación tiene una estrecha relación con la alfabetización audiovisual: "la capacidad de decodificar, evaluar y comunicarse en una variedad de medios (video, ordenadores, radio, prensa, televisión, Internet, etc.)” (AML, cit. Gómez y Patiño, 2015). Es de extrema importancia mejorar las competencias de los ciudadanos en este ámbito porque en la actualidad la imagen en un sentido amplio, o si se prefiere, todo aquello que llega en formato pantalla (y eso incluye también a los móviles) para acceder a Youtube, Instagram o Twitter, en ese orden, tiene una capacidad de penetración infinitamente superior a los textos que llegan sobre el papel.

Como ha declarado la Conferencia de Seguridad de Munich, el principal encuentro internacional de instituciones y expertos occidentales de seguridad, que se celebra anualmente desde 1963 en la ciudad alemana de Munich, la ciberdefensa no es suficiente para combatir la desinformación y los discursos del odio que en numerosas ocasiones la acompañan, sino que las instituciones democráticas tienen la obligación de apoyar la alfabetización mediática, fortalecer sus esfuerzos de comunicación y edu- 
car a sus ciudadanos. La respuesta no se encuentra en legislar para prohibir noticias falsas o crear supuestas agencias de la verdad, a menos que los Estados se conviertan en antiliberales. Prevenir "un mundo de la posverdad en el que nada es verdad y cualquier cosa es posible" es una tarea de toda la sociedad en su conjunto (Munich Security Conference, 2017).

Por último, conviene destacar también la decidida apuesta de la Unión Europea por el impulso de políticas de gobierno abierto y de transparencia, entendiendo que el acceso a la información y la rendición de cuentas de los Gobiernos es un instrumento de fortalecimiento institucional y de cohesión social para aumentar la confianza de la ciudadanía en sus instituciones democráticas.

\section{Conclusión}

Lejos de desaparecer el discurso o los delitos de odio en Europa, estamos asistiendo a una preocupante proliferación y crecimiento de ambos a resulta del incremento de la desinformación en la era digital en volumen y en rapidez de diseminación. Esto hace necesario emprender una nueva exégesis del discurso del odio con el fin de mejorar las herramientas para su prevención, cuando no paliativas.

La realidad europea de los últimos años, que engloba y pone a convivir situaciones como la multiculturalidad, producto de las migraciones de las últimas cuatro décadas, con la cultura del estado de bienestar y los nuevos medios relacionales, comunicacionales y tecnológicos, ha derivado en lamentables situaciones de odio. Las instituciones legisladoras y políticas europeas no pueden hacer caso omiso de la coyuntura existente y deben desarrollar una estrategia común y global en la lucha contra el discurso del odio, que integre las intervenciones parciales en diversas áreas y las diferentes iniciativas nacionales.

En nuestro recuerdo quedan tristes épocas del pasado reciente en Europa, donde el odio fraguó un discurso propagandístico a cuya expansión acompañó en tantas ocasiones la inacción jurídica y la pasividad política. El odio representa un gran riesgo para la estabilidad social de Europa, por lo que es una obligación de las instituciones comunes europeas y nacionales impedir y contrarrestar la expansión de los discursos de odio y ser extremadamente vigilantes en la represión de los delitos de odio.

\section{Referencias}

Abejón, P., Tejedor, L., Gómez y Patiño, M., Risueño, I.; Osuna, C. y Dader, J. L. (2017). El uso de las webs, Facebook y Twitter en la comunicación electoral española de 2015: Una mirada impresionista. En: Dader, J. L. y Campos, E. La búsqueda digital del voto. Cibercampañas electorales en España 2015-16. Valencia: Tirant lo Blanch, pp. 75-140.

Blumler, J. (2016). The fourth age of political communication. Politiques de communication, 1 (6): 19-30.

Centro Criptológico Nacional (2019). Desinformación en el ciberespacio. CCN-CERT BP/13. Obtenido el 1 de abril de 2019 de http://cort.as/-HVh7

Comisión Europea (2016). Code of Conduct on Countering Illegal Hate Speech Online. Obtenido el 1 de abril de 2019 de http://cort.as/-HVh

Consejo Europeo (1997). Recommendation №. R (97) 20 of the Committee of Ministers to member states on "Hate Speech". Obtenido el 1 de abril de 2019 de http://cort.as/-HVhP

Consejo Europeo (2003). Additional Protocol to the Convention on Cybercrime, concerning the criminalisation of acts of a racist and xenophobic nature committed through computer systems. Obtenido el 1 de abril de 2019 de http://cort.as/-HVhp

Consejo Europeo (2015). ECRI General Policy Recommendation No. 15 on combating Hate Speech. Obtenido el 1 de abril de 2019 de http://cort.as/-HVhr

Consejo Europeo (2016). Declaración conjunta de los ministros de Justicia y Asuntos de Interior de la UE y los representantes de las instituciones de la UE con motivo de los atentados terroristas perpetrados en Bruselas el 22 de marzo de 2016. Obtenido el 1 de abril de 2019 de http://cort.as/-HVi2

Dader, J.L. (2017): Campañas políticas 'online': la realidad española frente al horizonte internacional del 'Tecnobildeo'. En: Dader, J. L. y Campos, E. (eds.) (2017). La búsqueda digital del voto. Cibercampañas electorales en España 2015-16. Valencia: Tirant lo Blanch, pp. 11-174.

Dader, J. L. y Campos, E. (eds.) (2017): La búsqueda digital del voto. Cibercampañas electorales en España 2015-16. Valencia: Tirant lo Blanch.

De Vreese, C., Boukes, M., Schuck, A., Vliegenthart, R. Bos, L. y Lelkes, Y. (2017). Linking survey and media content data: Opportunities, considerations, and pitfalls. Communication Methods and Measures, 11 (4): 221-244.

European Commission EU (2018). A multi-dimensional approach to disinformation. Report of the independent High level Group on fake news and online disinformation. Obtenido el 1 de abril de 2019 de http://cort.as/-HViD

Frau-Meigs, D. (2018). Societal costs of "fake news" in the Digital Single Market. Bruselas: European Parlament. Obtenido el 1 de abril de 2019 de http://cort.as/-HVi]

Gil de Zúñiga, H. y Diehl, T. (2017). Citizenship, social media, and big data: Current and future research in the social sciences. Social Science Computer Review, 35 (1): 3-9. 
Gil de Zúñiga, H., Ardèvol-Abreu, A., Diehl, T., Gómez Patiño, M. y Liu, J. H. (2019). La confianza en los actores institucionales en 22 sociedades. Análisis de la confianza en la política, la ciencia y los medios de comunicación en el mundo. Revista Latina de Comunicación Social, 74: 237-262. Obtenido el 1 de abril de 2019 de https://doi. org/10.4185/RLCS-2019-1329

Gobierno de España. Ministerio de Defensa (2017). Estrategia de Seguridad Nacional. Obtenido el 1 de abril de 2019 de http://cort.as/-HVij

Gómez y Patiño, M. y Bandrés, E. (2014). El neuromarketing: Una nueva disciplina para la investigación de audiencias y de la opinión pública. Icono 14, 12(2): 395-415. Obtenido el 1 de abril de 2019 de https://doi.org/10.7195/ri14.v12i2.666

Gómez y Patiño, M. (2015). Educando con los medios, una revisión desde los clásicos. Dos siglos de educación: de Freinet a Wikipedia. Hachetetepé: Educación y Comunicación, 11:119-130. Obtenido el 1 de abril de 2019 de http://cort.as/-HVj9

Gómez-Patiño, M.; Nogales-Bocio, A. I. y Esteban-Navarro, M. A. (2018). Comunicación Política y Opinión Pública 4.0. En: Marta-Lazo, C. (ed.). Calidad Informativa en la Era de la Digitalización: Fundamentos profesionales vs. Infopolución. Madrid: Dykinson, pp. 83-98.

López Ortega, A. I. (2017). Análisis y Evolución de los delitos de odio en España (20112015). Antropología Experimental, 17: 19-37.

Munich Security Conference (2017). Munich Security Report 2017. Post-Truth, PostWest, Post-Order? Obtenido el 1 de abril de 2019 de http://report2017.securityconference.de/

OSCE - ODIHR. Organization for Security and Co-operation in Europe - Office for Democratic Institutions and Human Rights (2009). Prosecuting Hate Crimes. A practical guide, 2009. Obtenido el 1 de abril de 2019 de https://www.osce.org/odihr/36426

OSCE - ODIHR. Organization for Security and Co-operation in Europe - Office for Democratic Institutions and Human Rights (2013). Hate Crimes in the OSCE Region: Incidents and Responses: Annual Report for 2012. Obtenido el 1 de abril de 2019 de https://www.osce.org/odihr/108395

Parekh, B (2012). Hate Speech: Is There a Case for Banning? En Herz, M. y Molnar, P. (eds.). The content and context of Hate Speech, Rethinking Regulation and Responses. Budapest, Central European University.

Pérez Calle, B. (2018). Estigmas, Rumorología y Pensamiento Económico. En: Rodríguez, M., García, A. y Cerdá, M. J. (coords.). La empresa comunica: protocolo y lenguaje organizacional, Barcelona: Gedisa, pp. 369-379.

Republique Française. Ministère des Armées (2017). Revue stratégique de défense et de sécurité nationale. Obtenido el 1 de abril de 2019 de http://cort.as/-HVkP

Rey Martínez, F. (2015). Discurso del odio y racismo líquido. En M. Revenga Sánchez (dir.). Libertad de expresión y discurso del odio. Madrid, Universidad de Alcalá / Defensor del Pueblo.
STEDH (2003). Sentencia del Tribunal Europeo de Derechos Humanos (Sección 1aㅡ), de 4 de diciembre de 2003, caso Müslum Günduz c. Turquía, apartado 37.

Transparency International (2015). Lobbying in Europe: Hidden Influence, Priviliged Access. Obtenido el 1 de abril de 2019 de https://www.transparency.org/whatwedo/publication/lobbying_in_europe

Túñez, M. y Sixto, J. (2012). Un escaño en Facebook: política 2.0, marketing viral y redes sociales. Vivat Academia, 118: 13-32.

UNESCO (2018). Journalism, 'fake news' \& Disinformation. Handbook for Journalism Education and Training. París: UN Educational, Scientific and Cultural Organization. Obtenido el 1 de abril de 2019 de http://cort.as/-HVko 